\title{
Comportamento consumidor, hábitos alimentares e consumo de televisão por escolares de Florianópolis
}

\section{Consumer behavior, eating habits and television viewing in students from Florianópolis, Brazil}

Giovanna Medeiros Rataichesck FIATES ${ }^{1}$

Renata Dias de Mello Castanho AMBONI²

Evanilda TEIXEIRA²

\section{RE S U M O}

\section{Objetivo}

Identificar o comportamento consumidor de escolares em relação aos seus hábitos alimentares e a influência da televisão.

\section{Métodos}

Trata-se de estudo piloto com 57 escolares com idades entre 7 e 10 anos, do ensino fundamental de uma escola particular localizada em Florianópolis (SC). Foi utilizado um questionário, desenvolvido especialmente para a pesquisa, e realizada avaliação antropo métrica. Os dados foram analisados utilizando testes de asso ciação (teste Qui-quadrado de Pearson - $\chi^{2}$ ) e análise de variância. As diferenças foram consideradas significantes quando $p<0,05$.

\section{Resultados}

Todos os estudantes tinham televisão em casa, sendo que $75,0 \%$ no próprio quarto. A grande maioria costumava beliscar enquanto assistia a televisão $(98,0 \%$ ), ou fazia as refeições com a televisão ligada $(89,5 \%$ ). O consumo semanal de hortaliças e frutas foi muito inferior ao recomendado segundo a pirâmide alimentar. Os espectadores freqüentes de televisão comiam menos verduras semanalmente do que os moderados. De acordo com a avaliação antropométrica, $23,6 \%$ dos estudantes apresentavam sobrepeso ou obesidade e $9,1 \%$ apresentavam adiposidade central.

\section{Conclusão}

Os hábitos dos estudantes indicam a necessidade de empregar estratégias educacionais que promovam a adoção de hábitos e comportamentos mais saudáveis.

Termos de indexação: Criança. Comportamento. Estado nutricional. Hábitos alimentares. Televisão.

\footnotetext{
${ }^{1}$ Universidade Federal de Santa Catarina, Centro de Ciências Agrárias, Programa de Pós-Graduação em Ciência dos Alimentos. Rod. Admar Gonzaga, 1346, Itacorubi, 88034-001, Florianópolis, SC, Brasil. E-mail: <gifiates@ccs.ufsc.br>

2 Universidade Federal de Santa Catarina, Centro de Ciências Agrárias, Departamento de Ciência e Tecnologia dos Alimentos. Florianópolis, SC, Brasil.
} 


\section{A B S T R A C T}

\section{Objective}

To identify the consumer behavior of a small sample of students (pilot study), regarding their eating habits and influence of television.

\section{Methods}

This is a pilot study with 57 students aging from 7 to 10 years attending the elementary grades of a private school located in Florianópolis (SC). A questionnaire developed specifically for this research was used and anthropometric assessment was done. The data were analyzed using association tests (Pearson's chi-square test $\left.-\chi^{2}\right)$ and analysis of variance. The differences were considered significant when $p<0.05$.

\section{Results}

All students had television sets at home; $75.0 \%$ in their own bedrooms. M ost of them snacked while watching television $(98.0 \%)$ or ate their meals with the television on $(89.5 \%)$. Weekly intakes of fruit and vegetables were way below the ideal quantities proposed by the food pyramid. Students classified as frequent viewers ( 4 or more times a day) ate fewer vegetables than did the moderate ones. Anthropometric evaluation indicated that $23.6 \%$ were overweight/obese and $9.1 \%$ presented central adiposity.

\section{Conclusion}

Results suggest that strategies must be employed, such as parent's counseling and development of school programs, in order to prevent possible health problems in the studied population.

Indexing terms: Children. Behavior. Nutritional status. Eating habits. Television.

\section{N T R O D U ÇÃ O}

Consumidor é o indivíduo que, sendo capaz de sentir vontades e preferências, ao procurar satisfazê-las, faz uma escolha e uma compra, avaliando o produto e suas alternativas ${ }^{1}$. Esta definição criou um campo de estudo emergente sobre o papel da criança como consumidora e, até o final do século $X X$, um grande volume de pesquisas se acumulou sobre este tópico. As crianças de sociedades ocidentais, de condição social mais favorável, são qualificadas como um importante mercado primário. Crianças também constituem um mercado futuro, pois já foi demonstrado que desenvolvem fidelidade a marcas em idade precoce e as atitudes favoráveis em relação a certas marcas tendem a durar até a idade adulta. Finalmente, crianças são influenciadores importantes, opinando sobre as compras diárias em seus lares².

Nos últimos anos, o poder econômico e a influência das crianças modernas sobre as decisões familiares aumentaram ainda mais: elas exercem influência considerável sobre as compras da família em várias categorias de produtos, incluindo brinquedos, roupas, eletrodomésticos e alimentos - principalmente cereais matinais, lanches e guloseimas 3 .

Essa situação provocou o surgimento de uma ampla gama de mensagens comerciais meticulosamente direcionadas ao público infantil: alimentos, especialmente guloseimas e fast foods, são os produtos mais freqüentemente anunciados durante os programas de televisão (TV) infantis ${ }^{4,5}$. Sabendo que a criança brasileira permanece em média 4 horas e 45 minutos por dia em frente à TV6 ${ }^{6}$, pode-se deduzir a quantidade de propagandas de alimentos pouco nutritivos assistidas ao longo dos anos.

A preferência infantil por guloseimas é amplamente reconhecida e sofre influência tanto ambiental quanto genética. No entanto, tais preferências estão cada vez mais divergentes das recomendações nutricionais, o que tem levado ao aumento da incidência de sobrepeso e obesidade no mundo todo ${ }^{7}$.

A ocorrência de sobrepeso e obesidade em crianças tem sido tradicionalmente associada ao hábito de assistir à TV, pois este promove o 
sedentarismo. Além disso, sabe-se hoje que os anúncios de alimentos veiculados na TV têm 0 poder de, efetivamente, promover seu consumo, influenciando diretamente os hábitos alimentares de criançass. 0 hábito de assistir à TV na infância ou na adolescência também foi associado positivamente com a ocorrência de baixo condicionamento físico, fumo e hipercolesterolemia na idade adulta 9 .

Quase toda a pesquisa sobre consumidor infantil foi conduzida em populações da América do Norte e da Europa Ocidental. Embora alguns aspectos do comportamento consumidor infantil possam ser considerados universais, pesquisas locais fornecem oportunidades valiosas para gerar informações sobre o que ocorre em outras partes do mundo. Desse modo, este estudo tem por objetivo identificar o comportamento consumidor de escolares de escola particular de Florianópolis (SC), em relação aos seus hábitos alimentares e à influência da televisão, buscando contribuir com um tema relevante e pouco estudado no Brasil.

\section{M ÉTO D O S}

Este foi um estudo piloto do tipo transversal, descritivo, de campo, desenvolvido em um período de três meses no ano de 2005, em uma escola particular próxima ao campus da Universidade Federal de Santa Catarina (UFSC), na cidade de Florianópolis (SC). 0 protocolo da pesquisa foi aprovado pelo Comitê de Ética para Pesquisa com Seres Humanos da UFSC (projeto no 293/2005).

Na primeira etapa do estudo, os 141 estudantes matriculados da primeira à quarta série do ensino fundamental, da referida escola, foram convidados a participar da pesquisa e receberam um questionário para ser preenchido em casa, sob supervisão dos pais. Apenas os estudantes que retornaram os questionários preenchidos, juntamente com o Termo de Consentimento Livre e Esclarecido assinado pelos pais, compuseram a amostra $(n=57)$.

A segunda etapa do estudo consistiu da coleta de medidas antropométricas (peso, altura e circunferência da cintura) para avaliação do estado nutricional. Os estudantes poderiam desistir em qualquer etapa do estudo caso desejassem, e a pesquisadora principal poderia ser contatada a qualquer momento, por telefone, para resolução de dúvidas.

A faixa etária de 7 a 10 anos foi escolhida porque neste período acontecem alguns dos mais importantes eventos em termos de desenvolvimento do comportamento consumidor: trata-se da fase analítica, na qual se desenvolve o pensamento simbolista, que permite uma compreensão mais sofisticada do mercado ${ }^{10}$. Também nesta faixa etária, a criança já compreende a intenção persuasiva do comercial e já conseguiu realizar o ato da compra independente, sem a interferência dos pais e com o seu próprio dinheiro, caso tenha acesso a ele ${ }^{11}$.

Um questionário semi-estruturado, contendo perguntas abertas e fechadas foi criado especialmente para o presente estudo, baseado na revisão da literatura; abordava dados sócio-demográficos, hábitos de consumidor, hábito de ver televisão, hábitos alimentares e atividade física. Os questionários foram entregues nas salas de aula, na presença da professora, após uma breve explanação sobre os objetivos da pesquisa. Os estudantes foram orientados a preencher o questionário eles mesmos, com ajuda dos pais. Os dados obtidos dos questionários foram tabulados no programa Excel for Windows ${ }^{\circledR}$ e foi criado um banco de dados para as análises estatísticas.

M edidas de peso, altura e circunferência da cintura foram tomadas de acordo com técnicas padronizadas ${ }^{12}$. Os dados de peso e altura foram utilizados para o cálculo do índice de massa corporal (IMC=peso/altura ${ }^{2}$ ) e diagnóstico de sobrepeso (IMC>percentil 85) e obesidade (IMC >percentil $95)^{13}$. Em crianças, a adiposidade central está correlacionada com padrões menos favoráveis de lipoproteínas sanguíneas e pressão arterial. Como o excesso de peso e os fatores de risco cardiovascular tendem a se perpetuar na idade adulta, a identificação precoce de grande adiposidade central em crianças é importante. Em vista disso, o uso da circunferência da cintura (CC) passou a ser adotado na identificação de adiposidade central 
de crianças e adolescentes na faixa etária de 3 a 19 anos $^{14}$.

Dois estudantes faltaram no dia da medição e foram excluídos desta análise.

$\mathrm{Na}$ análise estatística dos dados, foram utilizados o teste Qui-quadrado $\left(\chi^{2}\right)$ de Pearson para comparar as variáveis dicotômicas, e a análise de variância (ANOVA) para comparar as variáveis contínuas. O nível de significância foi estabelecido em $p<0,05$.

\section{RESULTA D O S}

Foram estudados 57 estudantes, com média de idade de 8,96 (desvio-padrão - $\mathrm{DP}=1,13$ ) anos, $49 \%$ do sexo masculino e $51 \%$ do sexo feminino. As características sócio-demográficas são apresentadas na Tabela 1. Os participantes eram relativamente representativos do conjunto dos alunos da escola em que foi feita a pesquisa.

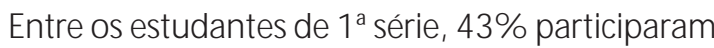
do estudo; $28 \%$ entre os de 2 a série, $38 \%$ entre

Tabela 1. Características sócio-demográficas de escolares do ensino fundamental de escola privada $(n=57)$. Florianópolis (SC), 2005.

\begin{tabular}{llcc}
\hline Variável & & $\mathrm{n}$ & $(\%)$ \\
\hline Idade/série & 7 anos/1a série & 9 & 16,0 \\
& 8 anos/2a série & 9 & 16,0 \\
& 9 anos/3a série & 15 & 26,0 \\
& 10 anos/4a série & 24 & 42,0 \\
Período de estudo & Matutino & 19 & 33,0 \\
& Vespertino & 38 & 67,0 \\
Escolaridade do pai & Fundamental & - & - \\
& Ensino médio & 14 & 24,5 \\
& Superior incompleto & 15 & 26,0 \\
& Superior completo & 26 & 46,0 \\
& Sem resposta & 2 & 3,5 \\
Escolaridade da mãe & Fundamental & 2 & 4,0 \\
& Ensino médio & 11 & 19,0 \\
& Superior incompleto & 11 & 19,0 \\
& Superior completo & 30 & 53,0 \\
& Sem resposta & 3 & 5,0 \\
& Trabalha & 54 & 95,0 \\
Ocupação do pai & Aposentado & 1 & 2,0 \\
& Sem resposta & 2 & 3,0 \\
& Trabalha & 44 & 77,0 \\
& Do lar/estudante & 9 & 16,0 \\
& Sem resposta & 4 & 7,0 \\
\hline & & &
\end{tabular}

os de 3ạ série e $49 \%$ entre os de 4ạ série. Nenhuma criança tinha necessidades especiais.

\section{Comportamento consumidor}

Grande parte dos entrevistados referiu ganhar mesada ou semanada $(61,5 \%)$, bem como presentes em dinheiro $(29,5 \%)$; os estudantes disseram preferir guardar o dinheiro $(82,5 \%)$ a gastá-lo de imediato. M eninos e meninas gastavam seu dinheiro de modos distintos: foram encontradas diferenças significativas nos gastos com material escolar, brinquedos e na categoria "outros" (Tabela 2). Neste item, que permitia que fosse especificado o artigo comprado, as meninas citaram roupas e acessórios. Quando considerado o conjunto, o gasto com alimentos apareceu em segundo lugar, atrás apenas de brinquedos.

A maioria dos estudantes $(77,5 \%)$ referiu que, às vezes ou sempre, costumava pedir aos pais que comprassem alimentos anunciados na televisão. Os alimentos e as bebidas mais pedidos aos pais no supermercado foram bolachas, flocos de milho açucarados, salgadinhos de pacote, seguidos por guloseimas doces, sucos "de caixinha", iogurte, refrigerantes e frutas. Em 98\% dos casos, os pais às vezes ou sempre costumavam trazer do supermercado os alimentos preferidos de seus filhos (Tabela 2).

Quando seus pedidos não eram atendidos pelos pais, a maioria referiu ficar triste, mas esquecer logo ( $45 \%$ das respostas); a segunda opção mais escolhida foi a de tentar convencer os pais a comprar o que queriam (34\%). A alternativa que mencionava conflito foi escolhida por apenas 9 estudantes (14\%).

\section{Hábito de assistir à televisão}

Todos os estudantes possuíam televisão em casa (média de 3,3 aparelhos por domicílio); $75,0 \%$ dispunham de televisão no próprio quarto e 73,5\% referiram não ter horários definidos pelos pais para assistir à TV. Mais da metade dos estudantes $(60,0 \%)$ referiu gostar de assistir a propagandas; $49,0 \%$ lembravam de propagandas de alimentos, sendo que as mais citadas foram ca- 
Tabela 2. Hábitos de escolares do ensino fundamental de escola privada em relação a comportamento consumidor, consumo de televisão, alimentação e atividade física, segundo sexo. Florianópolis (SC), 2005.

\begin{tabular}{|c|c|c|c|c|c|c|c|}
\hline \multirow{2}{*}{ Variável } & & \multicolumn{2}{|c|}{ Feminino $(n=29)$} & \multicolumn{2}{|c|}{ Masculino $(n=28)$} & \multicolumn{2}{|c|}{ Diferença entre sexos } \\
\hline & & $\mathrm{n}$ & $\%$ & $\mathrm{n}$ & $\%$ & $\chi^{2}$ & $\mathrm{p}$ \\
\hline Recebe mesada & $\mathrm{Sim}$ & 16 & 55,20 & 18 & 64,30 & 0,03 & 0,8720 \\
\hline $\begin{array}{l}\text { Recebe presentes } \\
\text { em dinheiro }\end{array}$ & $\mathrm{Sim}$ & 10 & 34,50 & 7 & 25,00 & 0,61 & 0,4340 \\
\hline \multirow[t]{6}{*}{ Gastos pessoais } & Livros/revistas & 10 & 34,50 & 8 & 28,60 & 0,23 & 0,6312 \\
\hline & Material escolar & 13 & 44,80 & 3 & 10,70 & 8,21 & 0,0041 \\
\hline & Brinquedos & 12 & 41,40 & 20 & 71,40 & 5,22 & 0,0227 \\
\hline & Lanches/doces & 9 & 31,00 & 10 & 35,70 & 0,14 & 0,7078 \\
\hline & Jogos/DVDs & 6 & 20,70 & 7 & 25,00 & 0,15 & 0,6982 \\
\hline & Outros & 8 & 27,60 & 2 & 7,14 & 4,12 & 0,0424 \\
\hline \multirow{3}{*}{$\begin{array}{l}\text { TV durante a } \\
\text { semana (vezes) }\end{array}$} & $<4$ x/dia & 22 & 75,80 & 21 & 75,00 & 0,001 & 0,9397 \\
\hline & $\geq 4$ x/dia & 7 & 24,10 & 7 & 25,00 & & \\
\hline & Média diária & 2,6 & $1,3^{*}$ & 2,9 & $1,10^{*}$ & $0,88 * *$ & 0,3520 \\
\hline \multirow{3}{*}{$\begin{array}{l}\text { TV durante o final } \\
\text { de semana (vezes) }\end{array}$} & $<4$ x/dia & 21 & 72,40 & 22 & 78,60 & 0,29 & 0,5892 \\
\hline & $\geq 4$ x/dia & 8 & 27,60 & 6 & $21,40 *$ & & \\
\hline & Média diária & 3,1 & $1,6^{*}$ & 2,6 & $1,40^{*}$ & $1,57 * *$ & 0,2150 \\
\hline Refeições & Média diária (nํ) & 3,9 & $0,8^{*}$ & 4,6 & $0,80 *$ & $10,91 * *$ & 0,0020 \\
\hline \multirow{3}{*}{$\begin{array}{l}\text { Consumo de } \\
\text { guloseimas (vezes) }\end{array}$} & $0-3$ x/semana & 20 & 69,00 & 18 & 64,30 & 0,14 & 0,7078 \\
\hline & 4-7 x/semana & 9 & 31,00 & 10 & 35,70 & & \\
\hline & Média semanal & 2,9 & $2,3^{*}$ & 3,0 & $1,60 *$ & $0,04 * *$ & 0,8500 \\
\hline \multirow{3}{*}{$\begin{array}{l}\text { Consumo de } \\
\text { frutas (vezes) }\end{array}$} & $0-3 x /$ semana & 10 & 34,50 & 8 & 28,60 & 0,23 & 0,6312 \\
\hline & 4-7 x/semana & 19 & 65,50 & 20 & 71,40 & & \\
\hline & Média semanal & 4,4 & $2,5^{*}$ & 5,3 & $2,0^{*}$ & $2,24 * *$ & 0,1400 \\
\hline \multirow{3}{*}{$\begin{array}{l}\text { Consumo de } \\
\text { verduras (vezes) }\end{array}$} & $0-3 x /$ semana & 17 & 58,60 & 11 & 39,30 & 2,13 & 0,1444 \\
\hline & 4-7 x/semana & 12 & 41,40 & 17 & 60,70 & & \\
\hline & Média semanal & 3,0 & $2,5^{*}$ & 4,4 & $2,20 *$ & $5,02 * *$ & 0,0290 \\
\hline \multirow[t]{3}{*}{ Refeições vendo TV } & Sempre & 6 & 20,70 & 11 & 39,30 & 2,35 & 0,1249 \\
\hline & Às vezes & 21 & 72,40 & 13 & 46,40 & 4,00 & 0,0455 \\
\hline & Nunca & 2 & 6,90 & 4 & 14,30 & 0,83 & 0,3634 \\
\hline \multirow[t]{3}{*}{ Belisca vendo TV } & Sempre & 7 & 24,10 & 9 & 32,10 & 0,45 & 0,5013 \\
\hline & Às vezes & 21 & 72,40 & 19 & 67,90 & 0,35 & 0,5541 \\
\hline & Nunca & 1 & 3,45 & 0 & - & 0,98 & 0,3215 \\
\hline Atividade física & Faz & 13 & 44,80 & 26 & 92,90 & 15,21 & 0,0000 \\
\hline
\end{tabular}

n: número; $\chi^{2}$ : qui-quadrado; p: nível de significância; *: média; **: F: razão de variância.

deias de fast food, bolachas, achocolatados e salgadinhos de pacote.

Foi perguntado em quais horários os estudantes costumavam assistir à televisão, em dias de semana e nos finais de semana, em um total de seis possibilidades diárias: na hora do café da manhã, durante a manhã, na hora do almoço, durante a tarde, na hora do jantar e antes de ir dormir. Os horários escolhidos com maior freqüência durante a semana foram às refeições $(35 \%)$ e à noite, antes de ir dormir (34\%); esta situação se repetiu no final de semana, embora tenha aumentado também a freqüência durante a manhã e a tarde. A penas duas crianças relataram não assistir à televisão aos finais de semana. Dos 57 estudantes que compuseram o estudo, 38 eram do turno vespertino, e destes, 32 costumavam assistir à TV pela manhã (84\% ). Dezenove eram estudantes do turno matutino, e destes, todos costumavam assistir à TV durante a tarde. Conforme o número de vezes ao dia em que relataram assistir à TV, os estudantes foram classificados em 
espectadores freqüentes (quatro vezes ao dia ou mais) ou moderados (menos de quatro vezes ao dia). Os espectadores freqüentes assistiam a mais TV do que os espectadores moderados, tanto durante a semana $(F=43,76, p=0,0000)$ quanto no final de semana $(F=32,67, p=0,0000)$, além de fazerem mais refeições com a TV ligada $\left(\chi^{2}=5,99, p=0,0143\right)$. Foram então comparados os consumos de frutas, verduras e guloseimas nos dois grupos. As diferenças são apresentadas na Tabela 3.

\section{Hábitos alimentares}

A grande maioria dos estudantes referiu consumir diariamente o desjejum, 0 almoço e 0 jantar, com um ou dois lanches intermediários (média de 4,2 refeições/dia). M eninos faziam mais refeições do que as meninas, com significância estatística (Tabela 2). As comidas favoritas mais citadas foram massas (macarrão, pizza, lasanha), seguidas por arroz com feijão, batata frita e pratos à base de carne. As bebidas favoritas mais citadas foram, respectivamente, sucos (naturais ou artificiais), refrigerantes, água e achocolatados. $M$ ais de $80 \%$ dos estudantes afirmou que os pais costumavam controlar o que eles comiam, para que evitassem principalmente guloseimas doces, salgadinhos de pacote, bolachas recheadas, alimentos gordurosos e refrigerantes. 0 consumo semanal de guloseimas, frutas e verduras referido pelos estudantes é apresentado na Tabela 2. 0 hábito de comer vendo televisão foi intensamente citado: $89,5 \%$ dos entrevistados referiram às vezes ou sempre fazer as refeições com a TV ligada e 98\% costumavam beliscar alguma coisa enquanto assistiam à TV (principalmente bolachas, salgadinhos de pacote, pipoca, frutas e guloseimas doces).

\section{Atividade física}

Quase 70,0\% dos estudantes faziam atividade física além da curricular obrigatória, realizada na escola, sendo a maioria do sexo masculino $(66,6 \%)$, de acordo com a Tabela 2 . A diferença na prática de atividade física por estudantes do sexo masculino e feminino foi estatisticamente significante $\left(\chi^{2}=15,21, p<0,005\right)$. As atividades favoritas citadas por ambos os sexos foram as mesmas: natação, futebol, bicicleta, patins, corrida e caminhada. 0 tempo de atividade física fora da escola totalizou uma média de 190 minutos por semana. A média semanal não diferiu estatisticamente entre meninos fisicamente ativos e meninas fisicamente ativas.

Os estudantes não relataram apenas atividades esportivas formais, com hora marcada, mas também atividades de lazer ativo em casa ou com amigos.

\section{Avaliação do estado nutricional}

Dos 55 estudantes avaliados, 13 (23,6\%) apresentaram sobrepeso ou obesidade. Quanto à avaliação da circunferência da cintura (CC), 5 estudantes $(9,1 \%)$ apresentaram diagnóstico de

Tabela 3. Consumo semanal de frutas, verduras e guloseimas de escolares do ensino fundamental de escola privada, classificados de acordo com a freqüência com que assistem à TV diariamente. Florianópolis (SC), 2005.

\begin{tabular}{|c|c|c|c|c|c|c|}
\hline \multirow{2}{*}{ Consumo alimentar } & \multicolumn{2}{|c|}{$\begin{array}{c}\text { Consumidores freqüentes de TV } \\
\text { (assistem } \geq 4 \text { vezes/dia) }\end{array}$} & \multicolumn{2}{|c|}{$\begin{array}{c}\text { Consumidores moderados de TV } \\
\text { (assistem }<4 \text { vezes/dia) }\end{array}$} & \multirow{2}{*}{$\mathrm{F}$} & \multirow{2}{*}{$\mathrm{p}$} \\
\hline & M & $\mathrm{DP}$ & M & DP & & \\
\hline Consumo semanal de verduras & 2,4 & 1,7 & 4,4 & 2,4 & 8,26 & 0,004 \\
\hline Consumo semanal de frutas & 4,8 & 2,3 & 4,8 & 2,3 & 0,00 & 1,000 \\
\hline Consumo semanal de guloseimas & 2,9 & 2,0 & 3,0 & 2,0 & 0,03 & 0,858 \\
\hline
\end{tabular}

M : média; DP: desvio-padrão; F: razão de variância; p: nível de significância. 
Tabela 4. Distribuição de escolares do ensino fundamental de escola privada $(n=55)$ de acordo com sexo e estado nutricional, segundo índice de massa corporal (IMC) e circunferência da cintura (CC). Florianópolis (SC), 2005.

\begin{tabular}{|c|c|c|c|c|c|c|c|}
\hline & & \multicolumn{2}{|c|}{ M asculino } & \multicolumn{2}{|c|}{ Feminino } & \multicolumn{2}{|c|}{ Total } \\
\hline & & $n$ & $(\%)$ & $n$ & $(\%)$ & $\mathrm{n}$ & $(\%)$ \\
\hline \multirow[t]{2}{*}{ IMC } & Eutrofia & 19 & 70,4 & 23 & 82,1 & 42 & 76,4 \\
\hline & Sobrepeso/obesidade & 8 & 29,6 & 5 & 17,9 & 13 & 23,6 \\
\hline \multirow[t]{2}{*}{$\mathrm{CC}$} & Normal & 24 & 88,9 & 26 & 92,9 & 50 & 90,9 \\
\hline & Adiposidade central & 3 & 11,1 & 2 & 7,1 & 5 & 9,1 \\
\hline
\end{tabular}

Nota: sobrepeso: IMC>percentil 85 para idade e sexo, obesidade $=I M C>$ percentil 95 para idade e sexo ${ }^{13}$; adiposidade central: circunferência da cintura>percentil 80 para idade e sexo ${ }^{14}$.

adiposidade central. Os resultados da avaliação do estado nutricional são apresentados na Tabela 4.

\section{I S C U S SÃ O}

No mundo todo, as crianças estão se tornando consumidoras ávidas de, praticamente, todos os tipos de serviços e produtos ${ }^{10}$. Neste estudo, pôde-se verificar que grande parte dos estudantes dispunha de dinheiro para gastar, e que $o$ alimento foi um dos itens com que mais gastavam seu dinheiro. Nos Estados Unidos, estima-se que anualmente crianças gastem mais de US\$7 bilhões, somente em comida e bebida ${ }^{11}$. Ou seja, o poder de compra da criança moderna não pode ser menosprezado.

Os efeitos indesejáveis da propaganda, têm ampliado a familiaridade com o consumo e estimulado o conflito entre pais e filhos ${ }^{15}$. No entanto, as crianças estudadas apresentaram um comportamento dócil em relação à frustração de não ganhar o que queriam, quando queriam, evitando o confronto direto com os pais. 0 modo como as crianças se comportam, enquanto consumidoras, muda de acordo com o padrão de comunicação familiar: nas famílias que encorajam a comunicação na forma de orientação conceitual, as crianças tendem a desenvolver uma perspectiva de consumo independente, aumentando sua influência de compra tanto direta quanto indireta. Já nas famílias que encorajam a comunicação sócio-orientada, as crianças tendem a respeitar mais os padrões familiares de consumo, com maiores níveis de dependência 3 .

No presente estudo, 0 alimento foi o segundo item mais comprado pelas crianças. Em um estudo similar realizado no $\mathrm{Chile}^{16}$, guloseimas, doces e salgadas, e refrigerantes eram os alimentos mais comprados pelos estudantes, quando tinham dinheiro para gastar, sendo estes os alimentos anunciados em suas propagandas preferidas. Os autores concluíram que o hábito de ver televisão, associado à preferência por certos comerciais veiculados, tinha relação direta com o consumo de lanches e outros alimentos adquiridos por crianças na escola ${ }^{16}$. Em Florianópolis, onde 0 estudo foi conduzido, as cantinas escolares são proibidas por lei de vender doces, chicletes, salgadinhos fritos ou de pacote e refrigerantes ${ }^{17}$. No entanto, os estudantes ainda têm à sua disposição itens como sorvete, picolé, chocolate, mini pizza, cachorro quente e hambúrguer, e também se permite que tragam de casa o que quiserem.

A exposição de crianças à televisão, em geral, pode aumentar o risco de se transformarem em consumidores mal informados sobre alimentos. Apesar de os pais serem responsáveis por escolher a maioria dos alimentos que chega às cozinhas das famílias, as crianças são expostas a uma gama enorme de mensagens verbais e não verbais sobre comida nos anúncios da TV. Na atualidade, a televisão pode ser a fonte mais importante de informação nutricional, na qual as crianças aprendem sobre os "mais novos e melhores" produtos alimentícios ${ }^{18}$. 
Almeida et al. ${ }^{5}$ analisaram 432 horas de programação da TV aberta brasileira em dias de semana e 216 horas aos sábados, constatando que a categoria alimentos era a mais freqüentemente veiculada, representando $22,47 \%$ de todas as propagandas. Dos 1395 anúncios de produtos alimentícios veiculados, 57,80\% estavam no grupo da pirâmide alimentar representado por gorduras, óleos, açúcares e doces. Houve completa ausência de frutas e vegetais nos anúncios. A pirâmide construída a partir da freqüência de veiculação de alimentos na TV diferiu significativamente da pirâmide considerada ideal ${ }^{5}$.

Segundo os resultados deste estudo, cerca de $25 \%$ dos estudantes assistiam a TV quatro vezes ou mais por dia e foram classificados como consumidores freqüentes. A pesar de a aferição não ter sido feita em horas, parece provável que o consumo esteja bem acima do recomendado, que é de somente uma hora por dia ${ }^{9}$. As crianças brasileiras não vão à escola durante período integral, como nos EUA e em países da Europa; portanto, têm mais tempo para dedicar a atividades de lazer, tais como assistir à televisão. Esse fato pode apresentar um risco adicional à saúde, pois hábitos dietéticos e de vida pouco saudáveis, tais como alto consumo de televisão e de açúcar, tendem a aglomerar outros hábitos de risco na mesma pessoa, como a baixa ingestão de vegetais crus e frutas $^{19}$.

A média semanal de consumo de guloseimas pelos estudantes foi relativamente baixa $(3,0, D P=2,0$ vezes por semana). No entanto, as médias semanais de consumo de frutas ou suco natural $(4,7 \mathrm{DP}=2,3)$ e de verduras $(3,6 \mathrm{DP}=2,4)$ ficaram muito aquém do recomendado. Philippi et al. ${ }^{20}$, na adaptação da pirâmide alimentar para o padrão brasileiro, indicam que o consumo diário de hortaliças não deve ser inferior a 4 porções, e que o consumo de frutas deve incluir ao menos 3 porções por dia. Sendo assim, os estudantes estão levando 7 dias para consumir o que seria desejável em 1 único dia da semana.

M eninos consumiam mais frutas e verduras e faziam um número maior de refeições diárias do que as meninas, demonstrando hábitos mais saudáveis. Uma possível explicação para o baixo consumo destes alimentos é o fato de que pais que consomem poucas frutas e verduras tendem a pressionar seus filhos a comer, o que acaba desestimulando a ingestão de alimentos saudáveis por seus filhos ${ }^{21}$.

Também já foi demonstrado que os anúncios veiculados influenciam os pedidos de compra das crianças, sua compreensão sobre princípios de nutrição, bem como os tipos e quantidades de alimentos que escolhem ingerir ${ }^{18}$ - quanto mais horas de TV a criança assiste, maior é a ingestão de energia na forma de gordura, doces, salgadinhos e refrigerantes e menor é a ingestão de frutas e vegetais ${ }^{4}$.

Os resultados forneceram indicações de que os pais se preocupam com os hábitos alimentares dos filhos, apesar de comprarem e trazerem para casa os itens que eles mesmos não querem que os filhos consumam. Isso não quer dizer que esse comportamento deve ser desencorajado, pois pesquisas demonstram que estratégias alimentares que restringem 0 acesso de crianças a lanches e guloseimas tornam os alimentos proibidos mais atrativos ${ }^{22}$. Os pais devem ter consciência de que, como as preferências alimentares das crianças são aprendidas, também são passíveis de modificação, portanto crianças podem aprender a gostar de alimentos saudáveis, desde que sejam educadas para isto desde cedo ${ }^{7}$.

0 hábito de assistir à TV ocupava uma parte importante do dia dos estudantes, e fazer as refeições com a televisão ligada ou beliscar vendo TV foram situações comuns no cotidiano da amostra. Os padrões alimentares de crianças cujas famílias consideram a televisão uma parte normal de suas rotinas alimentares podem incluir menos frutas e vegetais e mais pizza, snack foods e refrigerantes do que os padrões alimentares de crianças de famílias nas quais assistir à TV e fazer refeições são atividades separadas ${ }^{23}$. Estudos também já demonstraram que crianças tendem a beliscar mais quando estão assistindo à TV, e que este hábito está associado ao aumento da ingestão 
energética total e de energia proveniente de gordura ${ }^{24-26}$.

Os dados do presente estudo corroboram tal afirmação, pois constatou-se uma diferença significativa no hábito de fazer as refeições assistindo à TV e no consumo semanal de verduras entre os grupos que assistiam à TV freqüentemente e moderadamente, embora não tenham sido encontradas diferenças no hábito de beliscar assistindo à TV. Arnas²7, em seu trabalho com 347 crianças com idades entre 3 e 8 anos, verificou que $89,6 \%$ das crianças tinham o hábito de beber ou comer algo enquanto assistiam à TV (principalmente frutas, refrigerantes, pipoca, amendoim, bolo, chips e doces/chocolates). 0 estudo também avaliou o conteúdo dos anúncios veiculados na $T V$ e verificou que a maioria era de doces/chocolates, chips, leite e laticínios. Olivares et al. ${ }^{16}$, em seu estudo com 786 escolares de 6 a 11 anos no Chile, verificaram que $99 \%$ deles assistia à televisão durante a semana, sendo que $20 \%$ assistiam mais de 3 horas por dia.

Neste estudo, quase $70 \%$ dos entrevistados relatou praticar esportes e/ou ter comportamento fisicamente ativo fora da escola. Foi encontrada uma diferença significativa nessa variável quando comparados meninos e meninas, resultado que está de acordo com o já reconhecido fato de que indivíduos do sexo masculino são mais envolvidos em esportes do que os do sexo feminino, seja qual for a idade da população ${ }^{28}$.

A avaliação do estado nutricional identificou uma proporção de $23,6 \%$ de crianças com sobrepeso ou obesidade, resultado similar ao obtido por um estudo conduzido com escolares de 7 a 9 anos em escolas públicas e privadas do município de Florianópolis $(22,2 \%)^{29}$. No entanto, esperava-se que as crianças com excesso de peso despendessem mais tempo vendo televisão diariamente e fossem menos ativas fisicamente do que seus colegas eutróficos, mas não foram encontradas diferenças significativas.

Algumas questões metodológicas devem ser consideradas quando da interpretação dos resultados aqui apresentados. Trata-se de um estudo conduzido em uma única escola particular, cuja participação dos estudantes se deu voluntariamente.

É possível que a influência da TV no ambiente doméstico esteja reduzindo o período durante o qual os pais são a principal força socializadora nas vidas de seus filhos. No entanto, 0 comportamento dos pais e a disponibilidade de alimentos saudáveis para as crianças dentro e fora de casa, devem ser fontes de reforço positivo, servindo de modelo.

0 grande percentual de crianças que assistem a televisão e a comprovada influência dos comerciais sobre suas preferências alimentares requerem uma estratégia urgente de educação nutricional que promova hábitos alimentares saudáveis. Também devem ser pensadas estratégias educacionais para reduzir o tempo que as crianças permanecem em frente à TV. Os resultados do presente estudo piloto podem servir de ponto de partida para pesquisas futuras e intervenções nutricionais que envolvam tanto a família quanto a escola.

\section{OLA B ORA DORES}

G.M.R. FIATES participou da elaboração do projeto de pesquisa, da coleta de dados, da tabulação e da discussão dos resultados e da elaboração do artigo. R.D.M.C. AMBONI e E. TEIXEIRA participaram da elaboração do projeto de pesquisa, da discussão dos resultados e da elaboração do artigo.

\section{REFERÊ N C IAS}

1. Ward S. Consumer socialization. J Cons Res. 1974; 1(1):1-14.

2. McNeal JU. Tapping the three kids' markets. Am Demographics. 1998; 20(1):37-41.

3. Rose GM, Boush D, Shoham A. Family communication and children's purchasing influence: a cross-national examination. J Bus Res. 2002; 55(11): 867-73.

4. Coon KA, Tucker KL. Television and children's consumption patterns. A review of the literature. Minerva Pediatr. 2002; 54(5):423-36. 
5. Almeida SS, Nascimento PCBD, Quaioti TCB. Quantidade e qualidade de produtos alimentícios anunciados na televisão brasileira. Rev Saúde Pública. 2002; 36(3):353-5.

6. Instituto M idiativa. Brasileiro vê TV mais de 5 horas por dia. [acesso em 14 Mar 2006]. Disponível em: <http://www.midiativa.org.br/index.php/midiativa/ content/view/full/2717>.

7. Birch LL. Development of food preferences. Annu Rev Nutr. 1999; 19(1):41-62.

8. Halford JCG, Gillespie J, Brown V, Pontin EE, Dovey TM. Effect of television advertisements for foods on food consumption in children. Appetite. 2004 42(2):221-25.

9. Hancox RJ, Milne BJ, Poulton R. Association between child and adolescent television viewing and adult health: a longitudinal birth cohort study. Lancet. 2004; 364(9430):257-62.

10. John DR. Consumer socialization of children: a retrospective look at twenty-five years of research. J Cons Res. 1999; 26(3):1-42.

11. McNeal J. Children as consumers of commercial and social products. Washington (DC): PAHO; 2000.

12. Lohman TG, Roche AF, M artorell R. Anthropometric standardization reference manual (Abridged Edition). Champaign (II): Human Kinetics Books; 1991.

13. Centers for Disease Controland Prevention. National Center for Health Statistic). CDC Growth Charts: United States [cited 2006 M ar 19]. A vailable from: <http://www.cdc.gov/growthcharts>.

14. Taylor RW, Jones IE, Williams SM, Goulding A. Evaluation of waist circumference, waist-to-hip ratio, and the conicity index as screening tools for high trunk fat mass, as measured by dual-energy $X$-ray absorptiometry, in children aged 3-19y. Am J Clin Nutr. 2000; 72(2):490-5.

15. Buijzen M, Valkenburg PM. The effects of television advertising on materialism, parent-child conflict and unhappiness: a review of research. J Appl Dev Psych. 2003; 24(4):437-56.

16. Olivares SC, Albala CA, Garcia FB, Jofre IC. Publicidad televisiva y preferencias alimentarias en escolares de la región metropolitana. Rev Méd Chile. 1999; 127(7):791-99.

17. Santa Catarina. Lei $\mathrm{n} 012.061$, de 18 de dezembro de 2001. Dispõe sobre critérios de concessão de serviços de lanches e bebidas nas unidades educacionais, localizadas no Estado de Santa Catarina. Lex: Diário Oficial do Estado de Santa Catarina. 200120 dez; 1.
18. Harrison K. Is "fat free" good for me? A panel study of television viewing and children's nutritional knowledge and reasoning. Health Commun. 2005; 17(2):117-32.

19. Ruano IR, Pujol MES. Hábitos de vida en una población escolar de Mataró (Barcelona) asociados al número de veces diarias que se ve televisión y al consumo de azúcares. Rev Esp Salud Pública. 1997; 71(5):487-98.

20. Philippi ST, Latterza RA, Cruz ATR, Ribeiro LC. Pirâmide alimentar adaptada: guia para a escolha dos alimentos. Rev Nutr. 1999; 12(1):65-80.

21. Fisher JO, Mitchell DC, Smiciklas-Wright $H$, Birch LL. Parental influences on young girls fruit and vegetable, micronutrient, and fat intakes. J Am Diet Assoc. 2002; 102(1):58-64.

22. Fisher JO, Birch LL. Restricting access to a palatable food affects children's behavioral response, food selection and intake. Am J Clin Nutr. 1999; 69(6): 1264-72.

23. Coon KA, Goldberg JG, Rogers BL, Tucker KL. Relationships between use of television during meals and children's food consumption patterns. Pediatrics. 2001; 107(1):1-9.

24. Borzekowski DL, Robinson TN. The 30-second effect: an experiment revealing the impact of television commercials on food preferences of preschoolers. J Am Diet Assoc. 2001; 101(1): 42-6.

25. Francis LA, Lee $Y$, Birch LL. Parental weight status and girlstelevision viewing, snacking and body mass indexes. Obes Res. 2003; 11(1):143-51.

26. Gore SA, Foster JA, Di Lillo VG, Kirk K, West DS. Television view ing and snacking. Eat Behav. 2003; 4(4):399-405.

27. Arnas YA. The effects of television food advertisement on children's food purchasing requests. Pediatr Int. 2006; 48(2):138-45.

28. Bellisle F, Rolland-Cachera MF, Kellogg Scientific Advisory Committee Child and Nutrition. Three consecutive $(1993,1995,1997)$ surveys of food intake, nutritional attitudes and knowledge, and lifestyle in 1000 French children, aged 9-11 years. J Hum Nutr Dietet. 2000; 13(2):101-11.

29. de Assis MAA, Rolland-Cachera M F, Grosseman S, Vasconcelos FAG, Luna MEP, Clavo MCM, et al. Obesity, overweight and thinness in schoolchildren of the city of Florianópolis, Southern Brazil. Eur J Clin Nutr. 2005; 59(9):1015-21

Recebido em: 10/10/2006

Versão final reapresentada em: 20/9/2007 Aprovado em: 10/10/2007 